\title{
Financial Risk and market Effects for the Congestion Costs of the electricity System in Italy
}

\author{
Enrico Maria Mosconi*, Stefano Poponi, Cecilia Silvestri \\ Department of Economics and Management, University La Tuscia, Via del Paradiso, 47, 01100, Viterbo - Italy
}

\begin{abstract}
The physical and structural constraints of the electricity grid economically and financially affect the operators imposing on them a set of measures designed to contain the problem of electric congestions. The Congestion costs occur in the electricity market when the power flows, equivalent to a projection mapping of energy injection and withdrawal, established by the "electricity stock exchange" and by "bi-lateral contracts", are incompatible with the transfer capacity guaranteed by the power grid, in required security conditions. Transfer restrictions in the national and transboundary transmission grid can potentially determine the market segmentation in different geographical areas, preventing the producers to compete freely to satisfy the overall demand in those areas. As a result of power congestions, those producers that have reduced limitations in the power transfer are obviously favored, also if in the presence of high marginal production costs and prices, leading to the constitution of pools of producers that de facto control the local market. Through a critical survey of the situation of the Italian electricity market the paper aims to describe and discuss the problem of power congestions costs, the electricity price formation and the congestion risk management.
\end{abstract}

Keywords: Power congestions, Electricity market, Congestion Risk

\section{Introduction}

The solving of economic and financial problems, deriving from the practical limitations on the power grid, is associated to a series of strategic actions and investments aimed at increasing the overall transfer and dispatching capacities, in particular in the high and extra high voltage (HV/EHV).

The continuity in the electricity supply and the voltage quality are just two of the elements that contribute to a correct management of the power grid [1]. At a managerial level, the operators face complex actions such as the continuous and instantaneous balance of the power grid [2]. This is not only related to the power loss in the transmission line, but also to the maintenance of the frequency and those particular factors such as energy loss, excessive load in the transmission lines and congestion costs. On a national scale it is the systemic dimension of the practical limits of the power grid that

${ }^{*}$ Corresponding author. Tel.: +390761357734

Fax: +390761357715; E-mail: enrico.mosconi@unitus.it

(c) 2015 International Association for Sharing Knowledge and Sustainability

DOI: $10.5383 /$ ijtee.10.02.004 generate congestions and reduce the efficient management of the power system. These methods can vary across countries [3]. Above all, it represents an obstacle when we consider the modalities and technologies used to produce, supply, transfer and use electricity.

The actions to improve system operations (energy market operators) concern both the short and the long period [4], [5].

In the long period, power congestions can be easily solved with strong investments in the electricity plants (transmission lines), in order to deal with major structural deficiencies on the power grid; create zonal electricity markets through the segmentation of the market resulting then in an increase of both quality and productivity of the National Transmission Grid (NTG) [6], [7]. Such problems also lead to consequences on an international scale. In the short-medium period all actions depend on the use of tools, especially financial tools, that will allow the operators to provide for the volatility of the assignment of fees for the transmission capacity and financial transmission rights related to the transfer capacity on the national power grid, concerning 
the production, transmission and consumption of electricity. It could happen, in fact, that in peculiar conditions the high volatility of electricity in the adjacent countries zones, the transmission right holder could find impossible to enter a transmission line agreement with both producers and consumers, in order to obtain an efficient use of the admissible hourly transmission. This implies that it is not always possible to seize the opportunity when it comes to saving, in terms of costs, on a regional, national or international level.

\section{Methodology}

Main aim of the present paper describes and discuss the evolutions of the problem of power congestions costs, the price formation and the role of renewable sources. In particular, it is aimed at a critical reconnaissance survey of the difficulties of the electricity grid and the role of congestion risk management in the power grid.

It adopts a qualitative research method approach based on the case study protocol defined by Yin [8]. It represents an exploratory study based on the documentary analysis [9], [10]. The sources of information cushion adopted for this case study are mainly formed by policies, report and official documents released by the Italian central government or institutional bodies.

The output of the survey represent a starting point, and possibly the guidelines, for further investigations on congestion control problem, for political leaders and for the national grid operator.

\section{Power Grid Criticalities}

It is common knowledge that the electricity national system is composed of a complex network of communicating vessels, where withdrawn electricity is not directly ascribable to the producer being it characterized by a complex system of transportation and distribution based on a series of power productions plants dislocated across the territory and by an importation power grid. Such power grids have undergone a process of refurbishment and segmentation, particularly in the importation system identifying the injection and withdrawal points in virtual foreign zones.

In order to procede to the solving of power congestions, eventually occurred during power injections or withdrawals, the Italian Energy Market Operator uses a simplified grid that shows only the most relevant limits of transfer between national and foreign zones and the limited production poles [6], [7]. In particular, the power grid is articulated as follows:

- Six geographical zones (Center- North, North, Center South, South, Sicily, Sardinia);

- Eight foreign virtual zones (France, Switzerland, Austria, Slovenia, BSP, Corsica, Corsica AC);

- Four national virtual zones, representing the limited production poles, or zones composed only of production units whose interconnection capacity with the power grid is inferior to the voltage of the same units [6].

The management of power congestions has established the definition of the structural transportation limits defined on the basis of set national transmission zones that take into consideration the triennial development plan of the National Transmission Grid (NTG) managed by Terna (2003-2005) and subsequent annual plans.
Each geographical or virtual zone is represented by a cluster of points of offer. They represent the smallest units on which the operators of the electricity market establish time programs for power injection and withdrawal, in execution of both bilateral contracts or following the acceptance of sale and purchase offer bids on the Electricity Market. The geographical conformation of such zones in Italy is functional to the management strategies adopted by Terna, in the power transfer across the whole peninsula, and is then communicated to Gestore dei Mercati Energetici (GME) along with the values of the related transfer limits.

In such situation, a zonal power flow control will be necessary in order to avoid power congestions on the grid.

Following the division of the power system into macro zones, the territorial imbalance of the overcapacity of the North, due to the greater supplied volumes of electricity and the zonal price difference, is immediately revealed.

According to the GME data [6] the above mentioned occurrence is related to renewable energy sources, in particular to the increase in their distribution across the national territory. The Terna data [5], [11], confirm the trend of the widening of the two-band rate North-South, and the success of renewable and non-programmable energy sources.

The increase of supply and, by consequence, of the injected power ascribable to renewable and non-programmable energy sources, has generated a series of criticalities on the power grid. Some of them are related to the determination of power overproduction in respect to zonal/national power demand, especially at minimum power flow, or concerning the necessity to guarantee an adequate reserve for the electricity system. These criticalities originate power congestions especially in the South-Center South zones where the imbalance between conventional and renewable sources is more evident.

Wind and photovoltaic power have a deep impact, not only on the distribution, but also on the voltage of the power grid. By consequence, the huge production of such power plants has determined especially in off-peak days, the need of additional measures, such as the necessity to acquire a greater primary and secondary-power reserve, in order not to damage the security of the power system as a whole, and in particular, with the photovoltaic where the regulatory framework consider the immediate electric power interruption exceeding the frequency interval 49.7:50.3 Hz [5].

Such limitations imposed a reorganization of the system of renewable energy sources through the means of "adequate and rapid" investment plans (inside the strategic plans of Terna) in order to guarantee both the minimum performance and the security and efficiency of the system, so to manage the frequency intervals in excess within the regulatory framework.

\section{Aspects of congestion}

The congestions of the power grid transportation system present structural and managing problems when the transmission capacity of an asset obtain an economic value [5], [12], [13] (Fig.1). The examples offered by the literature on congestive strategic behavior of the operators especially those who can count on a higher amount of electricity across the national territory (e.g. [14], [15], [16]). The main principle of such a strategy resides in the ability to take advantage of the criticalities of power transmission. The impossibility of transferring power in some segments of the power transmission line, the voltage required, leads in fact, to the use of more expensive power units in the downstream under network. 
Congestions are ascribable to several interconnected factors, such as the variability in electricity demand in relation with the lack of transmission plants, or the derivation from the deregulated electricity markets system that influences power supplies according to the different distribution of power flows. For this reason in Italy the Integrated Electricity Market Rules issued by Gestore dei Mercati Energetici (GME) considers, both for the Daily Electricity Market and the Arrangement Market, the actuation of a "zonal" strategy to solve zonal congestions characterized by the possible formation of market areas with different power selling price [17]: the market splitting at a national level, and the market coupling with neighboring countries. This type of intervention implies a zonal partition into geographical areas divided according to portions of the power grid that follow practical limitations in power exchange with the neighboring areas, and that guarantee, at the same time, the security of the electricity power grid. The segmentation of the market zones is necessary every time the established limits are exceeded, with the subsequent formation of different prices in each.

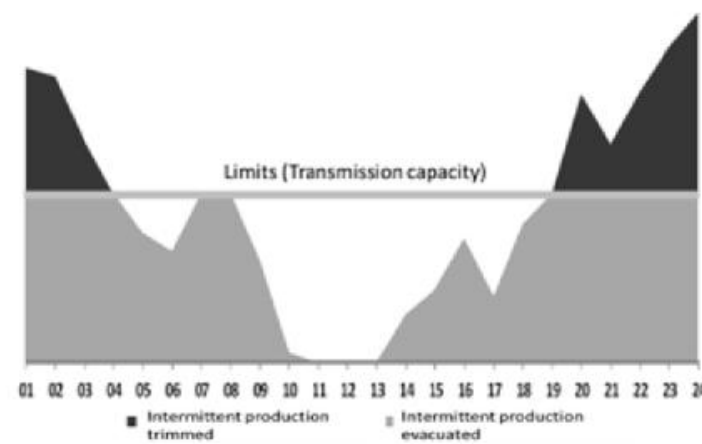

Figure 1. Example of the impact of hourly congestions in the power grid. (Source: Terna Strategic plan 2013-2015)

In this case, regardless of the algorithm used to calculate electricity price, we would normally have a higher price in those zones importing electricity [17].

Anyway, the algorithms used to establish which units should produce electricity is based on the maximizing of a function of social welfare of the system [15], [18], [19], limited though by the maximum admissible flows between the zones where the zonal price is determined by the equilibrium between zonal demand and offer bids. Whereas producers are paid at a zonal price, consumers will only pay the Single National Price (PUN).

The structure of electricity markets expose operators to two types of electricity price risk exposure:

- price volatility risk (exposure) in a period of time, that influences the purchase and sell in power markets or in the over the counter (OTC) market in bilateral contracts [2], [20], [21];

- volatility of payment risk for the transfer capacity right of use, related to the volatility of the electricity price in space, derived from grid congestions and, to the formation of different zonal prices according to the location of power plants over the counter (OTC) market in bilateral contracts [20].

\section{Power congestions, electricity price formation and congestion risk}

In the presence of power congestions and of a zonal splitting (market splitting), the difference between electricity price transferred within the same zones of buyers and sellers is measured by the differential of the value between two zonal markets, that is, the differential of power withdrawal price (paid by the demand) and the injection price (received by the offer). A solution to across borders power congestions at a European level can be represented by the market coupling [3], [22], [23], an implicit auction mechanism that cancel the inefficiencies in power exchanges, where the transfer capacity is allocated and valued according to the level of prices determined in national auction bids.

Physical constraints in the power transmission can put the execution of electricity buying and selling agreements in conflict with the security guarantee of the system. It is therefore necessary to manage with the maximum efficiency the programmed power injections and withdrawals, that is to operate through a central system, in order to execute the buying and selling agreements and organize the structural constraints of power transmission.

At a national level $40 \%$ of electrical overloads are located in the South, where the most critical zones are represented by the intersection areas between Puglia and Campania. In those areas, in fact, the incidence of risk of power congestion is very high, in particular in the primary power reserve of Campania [5]. The areas presenting a higher risk are those where the density of population and electricity consumption is greater. In particular for Florence, Rome, Milan and Naples the occurrence is ascribable to the transportation capacity of the power lines, to the scarce capacity to transform the High Voltage (HV) and Extra High Voltage (EHV) plants and to the reduced capacity of the power grid (mesh).

All this results in the "congestion cost", where the power load on the grid often favors the use of noncompetitive plants. Congestions on the primary power reserve lead to a limited competitiveness with the consequent reduction of the efficiency and economicity of the power system and the entrance of a new productive capacity in the system to the detriment of the security of demand.

Table 1 shows the general increase of the number of hours of congestion in the market zones involved in the occurrence in the period 2011-2012. On the whole, the increase is of 25\%, with the most significant value of the variation of the hourly energy blocks, represented in the North zones vs. Central zones by an increment of $73 \%$. The absolute value is attributed to the zone Rosanno vs. Sicily where it gets to 5,797 hours of congestion with a $\mathrm{n}$ increase of $32 \%$, whilst a reversed trend is recorded in the South v. C. North with a decrease of $51 \%$. 
Table 1. Total congestion hours in the two-year period 2010-2012 (Source: our processing on Terna data, 2013)

\begin{tabular}{|c|c|c|c|}
\hline \multirow[t]{2}{*}{ Macro areas } & \multicolumn{3}{|c|}{ Hours of congestions } \\
\hline & 2010-11 & 2011-12 & $\%$ Var \\
\hline South -> Center South & 1.382 & 1.449 & $4,8 \%$ \\
\hline Rossano/Brindisi -> South & 594 & North & -- \\
\hline *Brindisi/Foggia -> South & North & 838 & -- \\
\hline Center South->Sardinia & 1.611 & 1.562 & $-3,0 \%$ \\
\hline Rossano ->Sicily & 4.370 & 5.797 & $32,7 \%$ \\
\hline Center South-> Center North & 580 & 284 & $-51,0 \%$ \\
\hline North -> Center North & 250 & 433 & $73,2 \%$ \\
\hline Center North $->$ Center South & 188 & $\mathrm{Nd}$ & -- \\
\hline Sicily $->$ Rossano & North & 876 & -- \\
\hline Total & 8.975 & 11.239 & $25,2 \%$ \\
\hline
\end{tabular}

The imbalance between the allocation of the resources and the structural inefficiency of the power grid, represented by the frequency saturation of the exchange margin between the zones of the Day Ahead Energy Market (DAM), proves Sicily as the zone with the highest saturation capacity, in respect to the competent market zones and the highest differential level of zonal price (see Table 1).

The implementation of the power grid and a wider spreading of the offer, also related to renewable energy sources [2], [15], [24],[25], [26], has evidenced new criticalities, so that a new reorganization, that would seriously consider such constraints, is now necessary.

Several suggestions are offered by the literature on the topic, as for example the study of the widening of the geographical borders of virtual markets in relation to variable costs of the most efficient production unities previously excluded from production because of power congestions [3], [20]. To this decrease would correspond then an increase of dispatching costs, but of a reduced entity because applied to a relatively high amount of electrical power contained within the overall reduction of electricity costs paid by customers.

\section{Available transmission capacity and payment of transmission congestion fees in the segmented electricity market}

Costs associated with the transmission pricing allocation of the transfer capacity derive from the difference between zonal prices, according to which selling offer bids accepted in the Day Ahead Market (DAM) are calculated and the National Single Price (PUN) according to which the purchase offer bids accepted in that market are calculated [5].

In the presence of interzonal congestions, market operators signing bilateral contracts pay the fee for assignment of rights of use of transmission electricity (CCT).

Transmission capacity rights can be theoretically exchanged as obligation or optional bonds. This two types of bonds imply different mechanisms and effects depending on the holder of the bonds:

- with obligation bonds the holder receives the payment, in the case of a positive value, of the underlying asset and makes a payment, if the value is negative;
- with optional bonds the holder receives the payment, when the value of the underlying asset is positive, but does not make any payments in the case of a negative value.

De facto, the implementation of transmission rights as bonds allows a more efficient management of the power grid. As already seen in the case of physical transmission rights, the transactions generating power flows in the opposite direction in respect of those generating congestions (counterflows), allow the transfer of a higher power on the power lines. If the considered rights are in the form of obligation bonds, and an operator has bought that the transmission right for one transaction, that generates a counterflow and the holder is motivated to finalize the transaction related to such right, with the consequent implementation of the amount of transactions that can be programmed.

The CCT are not only technical tools of the electricity market but they also reveal useful information concerning the level of efficiency of some interconnections in the power grid. In particular, they highlight the limitations of the capacity in the border zones and help in dealing with the interzonal congestions (Table 2).

Table 2. Unitary Fees of Rights of Use of Trans-mission Capacity (CCT)- 2010-2012 (Source: our processing onTerna data, 2012)

\begin{tabular}{llll}
\hline Zonal Market & $\mathbf{2 0 1 0}$ & $\mathbf{2 0 1 1}$ & $\mathbf{2 0 1 2}$ \\
\hline North & 2,14 & 2,06 & 1,43 \\
Center North & 1,66 & 1,07 & 1,61 \\
Center South & 1,53 & 1,37 & 2,32 \\
South & 5,12 & 3,19 & 5,14 \\
Sicily & $-25,59$ & $-20,88$ & $-19,8$ \\
Sardinia & $-9,38$ & $-7,7$ & $-6,19$ \\
Foreign zones* & $-21,67$ & 18,28 & 24,29 \\
\hline
\end{tabular}

*aggregate value ref. France, Switzerland Austria, Slovenia, Bps, Greece, Corsica, Corsica.

In order to help market operators to cover the risks related to costs associated with the fluctuation of the power price in different nodes and zones of the grid, the law has considered the assignment by Terna to several market operators of some financial tools to cover power congestion costs (CCC and $\mathrm{CCP})$ defined "firm transmission rights" or fixed price of transmission.

CCC serve to cover the risk of volatility of the fee for the assignment of rights of use of transmission capacity (CCT), as stated in the resolution nr. 111/06 of the Authority for Electricity and Gas, that charges the Energy Market Manager (GME) and market operators.

In order to help market operators to cover the risks related to costs associated with the fluctuation of the power price in different nodes and zones of the grid, the law has considered the assignment by Terna to several market operators of some financial tools to cover power congestion costs (CCC and $\mathrm{CCP})$ defined "firm transmission rights" or fixed price of transmission.

CCC serve to cover the risk of volatility of the fee for the assignment of rights of use of transmission capacity (CCT), as stated in the resolution nr. 111/06 of the Authority for Electricity and Gas, that charges the Energy Market Manager (GME) and market operators. 
With the resolution nr. 205/04, the Authority for Electricity and Gas has considered the organization and definition, through competitive examinations, of useful tools to cover the risk of volatility of the fee for the assignment of rights of use of transmission capacity (CCT) for those operators entitled to manage dispatching points for power production and importing units.

The issue value of $\mathrm{CCC}$ decided by the energy market manager amount to $1 \mathrm{MW}$ and refers to a specific period (in hours) and to a specific connection between two nodes [20], and in particular to the CCP with unitary power value of $1 \mathrm{MW}$, on yearly or monthly base, and referred to each single limited production pole, as stated in art. 15 of the resolution nr. 111/06.

The holders of purchasesell agreements stipulated out of the bidding system can use such financial tools with the same benefits, too. In fact, in the presence of a nondiscriminatory purpose the holders of the above mentioned agreements must pay, to the power grid manager, a fee for the assignment of rights of use of transmission capacity equal to the difference between the equilibrium price in the withdrawal zone and that of the injection zone, of exactly the same fee conceded by the issuer of the CCC.

The issue of a CCC refers to a specific power transmission and require the issuer (the power grid manager) in the period of its validity, to make/receive hourly payments of the amount of the difference between the equilibrium price in the downstream zone and the equilibrium price of the upstream zone, equal to the total amount of power of the CCC. Conversely, the power grid manager will receive from the energy market manager, and from the holders of purchase and sell agreements stipulated out of the bidding system, the levy derived from the congestion costs. Therefore, if the power grid manager issued CCC over each transmission of the amount of the related available transmission capacity, the revenues deriving from congestion fees are of the same amount, for each hour, of the clearing fees concerning the issued CCC. The period of validity of such financial tools can be inferior to one year in order to facilitate the reallocation of the operators on a monthly or yearly basis, that is congruent with the duration of the ordinary electricity supply agreement.

$\mathrm{CCC}$ are technically agreements that put into execution foreign exchange transactions with fixed fee payment, predetermined and independent of the evaluation spot of the fee for the assignment of rights of use of transmission capacity [27].

They consider two types of evaluation of the power transmission capacity right:

- the implied value, when the holder of the CCC agreement can transfer predetermined hourly amounts of electricity in the interconnected zone, without any obligation to pay the fee resulting from the difference between the market price of the downstream zone (market of power destination) and the market price of the upstream zone (market of power production);

- expressed value, when the holder of the $\mathrm{CCC}$ receives from the issuer (if positive) or pay to the issuer (if negative) the difference between the equilibrium price of the downstream zone and the price of upstream zone for the hourly amount of electricity of the amount of the capacity stated in the CCC agreement.

The difference between the two types of evaluations consists of a greater flexibility, typical of the expressed value, that leaves room for a greater negotiability and remittance. Furthermore, the CCC can also be issued by different operators in order to allow an easier implementation of secondary markets related to CCC.

The Congestion Revenue Rights (CRR) is one of the parameters used to evaluate market segmentation and, by consequence, its efficiency.

It is not difficult to prove then that when we consider power transmission rights the condition of revenue sufficiency is always verified for all admissible power flows, and that it is not causing any infringement of transmission capacity limits on any power node. Even though, when considering the large number of the CCC agreements that meet such conditions, there arise the question of how to determine how many bonds are available and for which transactions.

A possible solution to the problem depends, on one hand, on the $\mathrm{CCC}$ required by the operators and, on the other, on the admissibility of derived power flows (in order to respect the condition of revenue efficiency). Therefore, the calculation of the overall transmission rights must be contextual to the purchase offers acquisition presented by the operators of the market. The mechanism adopted in this case is that of the concurrent auction: once known the purchase bids (coupling of maximum quantity-maximum price), transmission rights are assigned in order to maximize the revenues of the market manager according to transmission capacity limits on the nodes, so to guarantee the condition of revenue sufficiency.

Then, the power market manager issues the rights obtaining clearing revenues deriving from the application of the congestion fee, of the amount of the value of each congested transfer, the admissible power flow of that transfer, calculated on zonal equilibrium prices (Table 3 ).

\begin{tabular}{llll}
\hline $\begin{array}{r}\text { Table } 3 \text { Unitary } \\
\text { (CCes of Rights of Use of Transmission Capacity }\end{array}$ \\
\hline Typology & $\mathbf{2 0 1 0}$ & $\mathbf{2 0 1 1}$ & (Source: \\
\hline Total revenue & 238.050 .420 & 162.371 .071 & 205.904 .425 \\
Unit revenue & 1,6 & 1,12 & 1,58 \\
Market Coupling & - & 14.209 .491 & 69.782 .196 \\
Market Coupling & - & 12,29 & 19,15 \\
\hline
\end{tabular}

Therefore, for each node and in each hour of congestion capacity, the above mentioned clearing revenues amount to the mathematical product of available transmission capacity and the difference of the equilibrium prices, respectively, in the upstream and downstream flow. The same mechanism of rights assignment, as already mentioned, could apply to the necessary modifications of the assignment of optional transmission rights. In this case the power market manager cannot rely on the payments made by the holders of the rights of power flows in the opposite direction from the node congestion (counterflows). Such payments, in fact, are not due because they concern optional capacity rights. This implies then that the overall rights issued by Terna is more lim-ited than the obligation bonds.

Table 4 shows the number of CCC and CCP agreements assigned in the years 2011 and 2012 and the overall increase of the Base level. In particular, it must be noticed that the auction of CCC in the yearly peakload profil concerning the zone North is negative for the first time $(-0.10$ euro/MWh) [6], whilst the increase of the volatility of the relation between peak and off-peak prices and from the increase of the volatility of the PUN, rises to $8.8 \%(+1.5 \%$ yearly) (Table 4$)$. 
Table 4 CCC and CCP agreements for 2011 and 2012 (Source: Terna Development Plan, 2013)

\begin{tabular}{lllll}
\hline Period & Base & Peak & Base & Peak \\
\hline Year & 8.205 & 1.242 & 6.438 & 448 \\
Jan. & 2.584 & 987 & 5.001 & 445 \\
Feb. & 2.687 & 787 & 7.977 & 1.568 \\
Mar. & 2.750 & 160 & 6.471 & 2.697 \\
Apr. & 2.774 & 1.182 & 9.154 & 3.886 \\
May & 1.333 & 595 & 5.008 & 4.747 \\
Jun. & 2.006 & 1.449 & 6.542 & 2.612 \\
Jul. & 3.927 & 1.436 & 7.840 & 1.748 \\
Aug. & 2.214 & 1.395 & 5.160 & 426 \\
Sept. & 2.856 & 1.395 & 8.532 & 3.684 \\
\hline Oct. & 1.857 & 2.371 & 8.235 & 1.830 \\
\hline Nov. & 4.524 & 2.691 & 5.930 & 992 \\
\hline Dec. & 3.299 & 1.131 & 5.949 & 430 \\
\hline
\end{tabular}

The increase of supply related to the photovoltaic and eolic energy production has contributed with a massive thrust, especially in the south, to stabilize the rise of prices in maximum peak hours, indirectly supporting the off-peak quotations, concentrating the margin recovery on costs in the off-peak hours, by virtue of a higher market power induced by the minor presence of renewable energy supply.

\section{Discussion}

A CCC right in the form of obligation bond with a cut of 1 MW gives its holder, for each hour of the validity period, the right to receive and the obligation to make payments of the amount resulting from the difference between electrical power in the downstream zone of the referred transmission, and the value of the same amount of electricity in the upstream zone of the transfer. In both cases the value is referred to the equilibrium price in the different zones. In particular:

- in the hours when the above mentioned difference is positive, that is the equilibrium price of the downstream zone is greater than the equilibrium price of the upstream zone, the holder of the CCC has the right to receive the payment of that difference (by the issuer of the bond);

- in the hours when the difference is negative, that is, the equilibrium price of the downstream zone is smaller than the equilibrium price of the upstream zone, the holder of the CCC must pay that difference (in favor of Terna);

- in the hours when the transfer referred to the CCC is not congested, the above mentioned difference is null (because the equilibrium price has the same value in the two zones, respectively downstream and upstream, of the transfer zone) and no payment takes place.

Therefore, in reference to the power transmission between two neighboring, potentially congested zones only in one of the two directions, a CCC referred to the direction of the eventual congestion originate, in the hours of power congestion, payments in favor of its holder and so, it has a positive value. On the other hand, a CCC referred to the opposite direction from expected power flow, is committed to pay for every power congestion occurrence, and therefore it has a negative power. Conversely, in the case of purchase of an optional bond with cut of $1 \mathrm{MW}$, the holder receives, for each hours of the period of validity, the right to receive payments of the amount resulting from the difference, if positive, between the value of $1 \mathrm{MWh}$ of electricity in the downstream zone, and the value of the amount of electricity in the upstream zone, where, in both cases, the value is determined on the basis of the equilibrium price in different zones. In the case the above mentioned difference is positive, that it, the equilibrium price of the downstream zone is greater than the equilibrium price of the upstream zone, the holder of the optional CCC bond receives the payment of the difference from the issuer; in the hours when the mentioned difference is negative or null, that is, the equilibrium price of the upstream zone is smaller or equal to the equilibrium price of the upstream zone, no payment takes place. By consequence, the market is forced to proceed to the market fragmentation using the market splitting strategy so originating a zonal price of the downstream (withdrawal) undernetwork higher than the upstream (injection) zone.

All publications on the subject unanimously agree that such strategy can be used for speculation practices by the great producers with a higher productive capacity evenly distributed across the country and across the borders.

In a system that per se wouldn't be congested if the producers refrained from using strategies of market power dominance, one or more than one of them could increase profits by creating artificial congestions. In order to incentivize or disincentivize congestive strategic behavior, a strategic role is related to the mechanism of congestion resolution adopted by transmission market managers.

In the absence of a congestion, producers' prices coincide with the value of the PUN and it is therefore not necessary to proceed to the market splitting. In such a situation, a supplier insured against the risk of accidental transmission congestions of a power line, through the purchase of CCC does not receive any benefits in respect to another power operator.

If conversely, the transfer capacity between two points is reduced, it is the case of the creation of an installation of a temporary connection between two nodes that causes breakdowns on a power line, this can lead an multizonal operator, to act in order to maximize his production. This would imply the creation of bottlenecks that would congest the transfer on the temporary connection line between two points, so to exclude other operators from making bid offers. In order to achieve this goal the dominant operator takes advantage of expedients for lower pricing in the bid-offer mechanism. On the other hand, the market manager, in order to meet the requirements, is forced to proceed to a market splitting into two zones.

Such a mechanism leads to the creation of two zones, A and B, within which we find two prices different from the PUN.

- The operator could take advantage of such differential, and the GME could achieve its goal, that is to meet the load requirements of the "point" respecting the load limit on the power grid. The behavior of the producer depends then on several economic aspects that can be summarizes as follows: 
- the price originated by the supplier that is forced to pay the equivalent price of the fee for the rights of use of transmission capacity (CCT) for each transferred MW, equal to CCT=PUN-Pz injection;

- the number of acquired rights necessary to make a perfect coverage of the transaction in respect to a power congestion on the connection between two points of the power line;

- the purchase-cost of bonds related to the hammer price of the $\mathrm{CCC}$;

- the right to receive the payment of the amount given by Terna, equal to the difference between the value of electricity in the downstream zone and the value of the same energy in the upstream zone.

- The producer acts then according to the profit deriving from the difference between the reimbursements received by the power market manager for the power congestion and the cost related to its realization.

\section{Conclusion}

The splitting of the country market into geographical zones and the definition of injection and withdrawal programs allow to bypass, or limit, the criticalities related to structural limitations of the power grid system.

The maximization of the exchange of power in neighboring zones, within the security and exchange parameters, leads to the formation of zonal prices whose value is influenced, positively and negatively in turn, by power congestions. The cost deriving from a power congestion on a power link exposes market operators to a price volatility. In such a context the CCC represent an efficient financial tool to guarantee the operators a complete coverage of the fluctuation of prices that depends, as just said, not only on the inefficiencies or limitations of the power grid, but also on the trend of quotations of combustibles, the intermittency of renewable and non-programmable energies and the increased load on the power grid [2], [28].

The efforts lavished by Italian and European organizations are not only aimed at the overcoming of such difficulties but also to find an equilibrium to manage the capacity of international interconnection according to self-regulatory mechanisms, to pursue the goal of the harmonization of access fees to the power transmission market and to better, altogether, the efficiency of the procedures of allocation of the connection capacity [3], [22]. Against these urgencies it is possible to notice a substantial commitment on the part of Terna that is carrying out investment programs for the refurbishment of the national power grid. On the other hand, the data referring to 2012 [6] when compared with the 2011, underline a general increase of the amount of congestion hours that from an overall national perspective, is still too high. Such problems cannot be solved if the actions will not be targeted to the streamlining of the procedures related to the enforcement of the regulations for the refurbishment of the entire power grid. However, it is possible to use congestion revenues, as it happened in the past and is still happening today, not only as a mere reference index on which the efficiency of the transmission grid can be calculated but also as indicators of the necessity of future investments.

\section{References}

[1] R. H. Boroumand, "Electricity markets and oligopolistic behaviors: The impact of a multimarket structure," Res. Int. Bus. Financ., vol. 33, pp. 319-333, Jan. 2015.

[2] E. Koliou, C. Eid, J. P. Chaves-Ávila, and R. a. Hakvoort, "Demand response in liberalized electricity markets: Analysis of aggregated load participation in the German balancing mechanism," Energy, vol. 71, pp. 245-254, May 2014

[3] E. Pellini, "Measuring the impact of market coupling on the Italian electricity market," Energy Policy, vol. 48, pp. 322-333, Sep. 2012.

[4] Terna, "Resoconto intermedio di Gestione," 2012.

[5] Terna, "Piano di Sviluppo 2013," 2012.

[6] GME, "Relazione annuale 2012," 2013.

[7] GME, "Testo integrato della disciplina del mercato elettrico," 2015.

[8] R. K. Yin, Case Study Research: Design and Methods. Sage Publishing, CA, 1994.

[9] D. Silverman, Qualitative Research: Theory, Method and Practice. Sage Publications Ltd, 2008.

[10] D. Silverman, Qualitative Research. Sage publications, London, 2011.

[11] Terna, "Piano di Sviluppo 2014," 2013.

[12] M. Esmaili, H. A. Shayanfar, and N. Amjady, "Congestion management enhancing transient stability of power systems," Appl. Energy, vol. 87, no. 3, pp. 971-981, Mar. 2010

[13] Y. Xiao, P. Wang, and L. Goel, "Congestion management in hybrid power markets," Electr. Power Syst. Res., vol. 79, no. 10, pp. 1416-1423, Oct. 2009.

[14] M. Pantoš, "Market-based congestion management in electric power systems with increased share of natural gas dependent power plants," Energy, vol. 36, no. 7, pp. 4244-4255, Jul. 2011.

[15] A. Di Giorgio and F. Liberati, "Near real time load shifting control for residential electricity prosumers under designed and market indexed pricing models," Appl. Energy, vol. 128, pp. 119-132, Sep. 2014.

[16] M.-C. Chang, "Electricity tax subsidizing the R\&D of emission-reducing technology: The double dividend effect under FIT regime," Int. J. Electr. Power Energy Syst., vol. 62, pp. 284-288, Nov. 2014. 
[17] M. Marracci and D. Poli, Meccanismi di formazione del prezzo di borsa dell'energia su base zonale e nodale. Milano, AEI., 2004.

[18] A. Kumar, S. C. Srivastava, and S. N. Singh, "Congestion management in competitive power market: A bibliographical survey," Electr. Power Syst. Res., vol. 76, no. 1-3, pp. 153-164, Sep. 2005.

[19] M. Esmaili, F. Ebadi, H. A. Shayanfar, and S. Jadid, "Congestion management in hybrid power markets using modified Benders decomposition," Appl. Energy, vol. 102, pp. 1004-1012, Feb. 2013.

[20] Authority for Electricity and Gas, "Indagine conoscitiva sullo stato della liberalizzazione dei settori dell'energia elettrica e del gas naturale (IC22)," 2005.

[21] A. Shcherbakova, A. Kleit, and J. Cho, "The value of energy storage in South Korea's electricity market: A Hotelling approach," Appl. Energy, vol. 125, pp. 93102, Jul. 2014.

[22] P. N. Biskas, D. I. Chatzigiannis, and A. G. Bakirtzis, "Market coupling feasibility between a power pool and a power exchange," Electr. Power Syst. Res., vol. 104, pp. 116-128, Nov. 2013.
[23] G. Oggioni and Y. Smeers, "Market failures of Market Coupling and counter-trading in Europe: An illustrative model based discussion," Energy Econ., vol. 35, pp. 74-87, Jan. 2013.

[24] M. Carlini, C. S., E. Allegrini, and T. A., "Efficient energy supply from ground coupled heat transfer source," in ICCSA Part II, LNCS, 2010, pp. 177-190.

[25] M. E.M., C. M., C. S., A. E., M. L., and A. di T. M., "Economical Assessment of Large-Scale Photovoltaic Plants: An Italian Case Study," in Computational Science and Its Applications ICCSA 2013, 2013.

[26] M. Carlini and S. Castellucci, "Modelling the vertical heat exchanger in thermal basin," in ICCSA 2011, Parte IV, LNCS, 2011, pp. 277-286.

[27] Authority for Electricity and Gas, "Relazione annuale sullo stato dei servizi e sull'attività svolta,” 2012.

[28] MacDonald Mott., "Impact assessment on European electricity balancing market, Final Report for EC DG ENER/B2/524/2011.," 2013. 